\title{
Effect of soy cake powder, milk fat and sugar on the body and texture of soy fortified burfi
}

\author{
Tarun Verma* and Jai Singh \\ Department of Animal Husbandry and Dairying, Institute of Agricultural Sciences, \\ BHU, Varanasi-221005, India \\ *Email: tarunverma.bhu@gmail.com
}

\begin{abstract}
Burfi, an indigenous dairy product has been prepared using soya cake powder and named as soy fortified burfi. The effect of the addition of milk fat, sugar and soya cake powder on the manufacturing of soy fortified burfi was analyzed. The formulation of soy fortified burfi with $4.59 \%$ milk fat, $19.24 \% \mathrm{SCP}$ and $26.93 \%$ sugar was considered to be the most appropriate with best Body and Texture. The predicted score of the suggested formulation was 8.31 for the body and texture.
\end{abstract}

Key words Soya cake powder (SCP), milk fat, sugar, soy burfi.

Paper Cited: Verma, T. And Singh, J. (2016). Effect of soy cake powder, milk fat and sugar on the body and texture of soy fortified burfi. South Asian Journal of Food Technology and Environment, 2(1): 335-344.

Received: 18/01/2016 Revised: 30.01.2016 Accepted: 07/02/2016

\section{Introduction}

Burfi is a sweet, square shaped or rectangular Indian confection prepared with khoa based. During its preparation sugar is added in different proportions and other ingredients incorporated according to the demand of consumers. It is also called as Indian cheesecake. Some of the most common varieties of burfi include besan burfi, kaju burfi, pista burfi, kesar burfi, rava burfi, mawa burfi, milk burfi, white burfi, chocolate barfi, mango barfi, coconut barfi, jackfruit barfi, rice flakes barfi, tricolor burfi, apple burfi and so on. Highintensity low-fat and protein enriched burfi provide consumers with many benefits, both psychologic and physiologic. Soya protein is complete (with all essential amino acids) and is as good as milk and egg protein. It also contains all the essential fatty acids, calcium, magnesium, lecithin, riboflavin, thiamine, fiber, folic acid and iron. Soya bean is high in fiber and has a low glycaemic index which helps in better control of blood sugar levels. It have a balancing effect on hormones, enhance blood cholesterol reductions, reducing the risk of hot flushes in menopausal women, control osteoporosis (Unlike animal protein, soya protein decreases calcium excretion from the body), improved vascular function, reduction of blood pressure, antioxidant protection of LDL cholesterol and inhibition of platelet activation are other known cardiovascular effects of soya and its constituent isoflavones (Anderson et al., 1995). On the basis of sensory evaluation, Arora et al. (2007) have shown the possibility of using low-calorie sweeteners in the preparations of indigenous dairy products, i.e., burfi. But no work has been reported on the effect of soya cake powder (byproduct of soy industries) on the Body and Texture of indigenous dairy products, viz. burfi. Hence, in view of the significance of soya cake powder in dairy products, an attempt has been made to study the Body and Texture and the possibility of using soya cake powder in the preparation of indigenous dairy products, i.e., soy fortified burfi. 


\section{Materials and methods}

Protein enriched Soy fortified burfi was prepared by following the traditional method of preparation (Sachdeva and Rajorhia, 1982; Arora et al., 2007 \& 2010 and Chetana et al., 2010) with slight modification for soyacontaining product (Verma, 2014) in the Dairy Technology Laboratory of the Department of Animal Husbandry and Dairying and the Centre of Food Science and Technology, Banaras Hindu University (BHU), Varanasi (India). Twenty trials with different levels (Table 1) were conducted to obtain a combination of selected parameters using Central composite rotatable design (CCRD) for the production of soy burfi.

The sensory evaluation of the product was performed using the procedures given by Amerine et al., (1965). The data obtained during the present investigation were suitably analyzed by employing response surface methodology (RSM) to optimize the various parameters. ANOVA was performed to validate the RSM optimization. The experimental data obtained from the design were analyzed by the response surface regression procedure using the following second order polynomial equation:

$\mathrm{Y}_{\mathrm{i}}=\beta_{\mathrm{o}}+\sum \beta_{\mathrm{i}} \mathrm{X}_{\mathrm{i}}+\sum \beta_{\mathrm{ii}} \mathrm{X}_{\mathrm{i}}^{2}+\sum \beta_{\mathrm{ij}} \mathrm{X}_{\mathrm{i}} \mathrm{X}_{\mathrm{j}}$

Where, $Y_{i}$ was the predicted response, $\beta_{0}$ was a constant, $\beta_{i}$ was the $i^{\text {th }}$ linear coefficient, $\beta_{\mathrm{ii}}$ was the $\mathrm{i}^{\text {th }}$ quadratic coefficient and $\beta_{\mathrm{ij}}$ was $\mathrm{ij}{ }^{\text {th }}$ interaction coefficient, and $\mathrm{X}_{\mathrm{i}} \mathrm{X}_{\mathrm{j}}$ were independent variables.

The second order polynomial coefficients were calculated using the package design expert version 8.0.3.1 to estimate the responses of the dependent variable. The second order polynomial equation was employed to fit the experimental data.

Using a CCRD, levels of variables viz. milk fat, soy cake powder and sugar were selected through 20 experiments (Table 1). Constraints used for the formulation for soy fortified burfi were depicted in the Table 4. In these quadratic polynomial equations $\mathrm{A}, \mathrm{B}$ and $\mathrm{C}$ are coded terms for the three variables, i.e. milk fat, soy cake powder and sugar, respectively. In the Design Expert software, the response data were analyzed by default. Some raw data might not be fitted and transformations which apply a mathematical function to all the response data might be needed to meet the assumptions that make the ANOVA valid.

The model terms in the equations are those remained after the elimination of insignificant variables and their interactions. Based on the statistical analysis, the models were highly significant with very low probability values $(\mathrm{P}<0.0001)$. It is shown that the model terms were significant at the $99 \%$ confidence level. The square of correlation coefficient for each response was computed as the coefficient of determination $\left(\mathrm{R}^{2}\right)$. It showed high significant regression at $95 \%$ confidence level. The value of the adjusted determination coefficient (adjusted $\mathrm{R}^{2}$ ) was also high to prove the high significance of the model (Khuri and Cornell, 1987). The predicted versus actual plot for the eight responses is also plotted (Fig. 3). It shows that the actual values are distributed close to the straight line $(\mathrm{y}=\mathrm{x})$ with relatively high values of $R^{2}$ (Table 2 ).

The models adequacy was tested through lack of- fit F-tests (Montgomery, 1997). The lack of fit results were not statistically significant as the $\mathrm{P}$ values were found to be greater than 0.05 . Adequate precision is a measure of the range in predicted response relative to its associated error or, in other words, a signal to noise ratio. Its desired value is 4 or more (Mason et al., 2003). The value was found to be desirable for the all models. Simultaneously, low values of the coefficient of variation $(\mathrm{CV})$ indicated good precision and reliability of the experiments as suggested by Ahmad et al., (2005).

\section{Results and Discussion}

The coefficient estimates of texture showed that the linear model terms for milk fat (A) and the quadratic model term for milk fat $\left(\mathrm{A}^{2}\right)$, soy cake powder $\left(\mathrm{B}^{2}\right)$ and sugar $\left(\mathrm{C}^{2}\right)$ had significant effect $(P<0.05)$ on texture of the product. However, quadratic interactive model term $(\mathrm{AB}, \mathrm{AC}, \mathrm{BC})$ were found to be insignificant $(P>0.05)$ with a probability value larger than 0.05 . In order to simplify the model, these insignificant model terms were eliminated. 
The regression equation obtained in terms of coded factors for the effect of variables on body and texture of soy fortified burfi could be described by the following equation:

Body \& Texture $=+8.33+0.26 * \mathrm{~A}-0.34 * \mathrm{~A}^{2}-$ $0.78 * B^{2}-0.21 * C^{2} \ldots(1)$

As it is noted in Eq. (1), the main-order effects of milk fat had positive impacts on the response while second-order effects of milk fat, soy cake powder and sugar had negative impacts on the response. ANOVA F-value (Table 2) was determined to examine the goodness of fit for the developed model. The F-value (17.87) for the model of body \& texture was significant $(P<0.05)$. It indicates that the model can be used to navigate the design space. In order to confirm the selected model, the diagnostic plots such as the predicted versus actual value (Fig. 3 a) and normal probability plot (Fig. 3 b) of the studentized residual provided by the Design Expert software were prepared to judge the model adequacy. In Table 2, the values of $\mathrm{R}^{2}$ and adjusted $\mathrm{R}^{2}$ were evaluated as 0.94 and 0.88 , respectively, showing a good agreement between the predicted and actual data. The 'Pred R-squared' of 0.6951 is in reasonable agreement with the 'Adj R- squared' of 0.8888. "Adeq Precision" value 12.88 indicates an adequate signal. The "Lack of Fit F-value" of 1.59 implies the Lack of Fit is not significant relative to the pure error. The average body and texture score of soy fortified burfi varied from 5.89 to 8.55 (Table 3).

In order to gain a better understanding of the interaction effects of variables on body and texture score of soy fortified burfi, two and three dimensional contour plots for the measured response were formed based on the model (Eq. 1). Fig. 2a-2c shows the plots of the model for variation in body and texture score of soy fortified burfi as a function of milk fat, soy cake powder and sugar. As can be seen in Fig. 2a-2c, almost the same trends were found in all the three plots. It is clear from the figures and Eq. (1) that the most significant factor on the response is milk fat. So that, as the milk fat increased the response was increased. It should be noted that the sugar did not have significant effect on the response. It is proven by perturbation plot (Fig. 4). The perturbation plot shows the comparative effects of the variables on the response. A steep curvature in milk fat (A curve) and SCP (B curve), shows that the response was very sensitive to this factor. The comparatively semi-flat $\mathrm{C}$ curves show less sensitivity of the body and texture to alter with respect to a change in sugar level. In other words, the sugar (in the range studied) have no major function in the treatment process when comparing body and texture score of soy fortified burfi.

It is quite clear from the Fig. 1 (a \& c) that milk fat is positively correlated $(\mathrm{P}<0.05)$ with the texture. This finding is at par with the report of Hardi et al., (2001) who found that fermented milk beverages having high milk fat content had a better texture, as compared to low fat samples. Lachance, (1994) and Kilara, (1998) also reported that fat plays a major role in most food texture, as it contributes to rheological characteristics such as body and texture. Further, as the SCP levels increased from $10 \%$ to $20 \%$ (Fig. 1 a), the body and texture scores apparently increased. Thereafter, it decreased significantly $(\mathrm{P}<0.05)$. Similar to our finding, Katara and Bhargava, (1990) had reported that channa samples become softer with increased addition of soy milk to cow milk. In hold up of present analysis, $20 \%$ level of soy-fortification was the best in soy-fortified maize dough (Anna et al., 2005, Addo et al., 1993) and soy-fortified bakery product (Masur et al., 2009). In contrast to present finding, the level of soy-fortification is 0 to $12 \%$ (Yanez et al., 1982) and $2-10 \%$ (Mishra et al., 1991; Dhingra and Jood, 2002) in defatted soy flour enriched bread, $40 \%$ in yamsoy mixture (Achi, 1999) and $6.66 \%$ in soyfortified Gulabjamuns (Singh et al., 2011).

This initial increase in texture score may be due to bio-adhesive property (Lin et al., 2012; Gu and $\mathrm{Li}, 2011$ ) and water binding capacity (Singh et al., 2010) of defatted soy flour. But with increased level of SCP above $20 \%$ causes raised total solid content in soy 
fortified burfi resulting granular texture which decreases its score. Increasing levels of sugar from $10 \%$ to $20 \%$ resulted minor increase (Fig. 2 b) in texture scores, thereafter, it decreases gradually. Sucrose helps to form a network and create a binding effect in the product. Hence, the inclusion of sugar improved the body and texture of the product. After certain saturation level of sugar i.e. $20 \%$ it decreased texture gradually. These are in conformation with those reported by Arora et al., (2007, 2010) who reported highest score for body and texture in control burfi as compared to burfi sweetened with low calorie sweeteners. Contrarary to our findings for yoghurt (Patel, 2010) and burfi with honey (Kadam, 2010) concluded that there was no significant difference in score for body and texture with different levels of sugar and honey, respectively.

\section{Conclusion}

Soy fortified burfi having good body and texture can be prepared with appropriate levels of milk fat, soy powder and sugar in the mixture.

Table 1: Experimental runs and actual values of factors used in central composite rotatable design

\begin{tabular}{|c|c|c|c|c|}
\hline & \multicolumn{3}{|c|}{ Variables } & Attributes \\
\hline Trial No. & Milk Fat (\%) & Soya Cake Powder (\%) & Sugar $(\%)$ & Body \& Texture \\
\hline 1 & 3 & 30 & 35 & 6.8 \\
\hline 2 & 4 & 20 & 30 & 8.55 \\
\hline 3 & 3 & 10 & 25 & 7.31 \\
\hline 4 & 4 & 20 & 21.59 & 7.53 \\
\hline 5 & 5 & 10 & 35 & 7.2 \\
\hline 6 & 3 & 10 & 35 & 6.89 \\
\hline 7 & 4 & 3.18 & 30 & 6.12 \\
\hline 8 & 4 & 20 & 30 & 8.2 \\
\hline 9 & 4 & 20 & 38.41 & 7.7 \\
\hline 10 & 4 & 20 & 30 & 8.51 \\
\hline 11 & 5.68 & 20 & 30 & 7.93 \\
\hline 12 & 5 & 30 & 35 & 7.22 \\
\hline 13 & 4 & 20 & 30 & 8.45 \\
\hline 14 & 2.32 & 20 & 30 & 6.58 \\
\hline 15 & 4 & 20 & 30 & 8.4 \\
\hline 16 & 5 & 30 & 25 & 7.02 \\
\hline 17 & 4 & 20 & 30 & 7.94 \\
\hline 18 & 5 & 10 & 25 & 7.6 \\
\hline 19 & 4 & 36.82 & 30 & 5.89 \\
\hline 20 & 3 & 30 & 25 & 6.75 \\
\hline
\end{tabular}


Table 2: ANOVA and Coefficient Estimate of Body \& Texture.

\begin{tabular}{|l|c|c|c|}
\hline \multirow{2}{*}{ Source } & Degree of freedom & F value & Coefficient Estimate \\
\cline { 2 - 4 } & & Body \& Texture & Body \& Texture \\
\hline Model & 9 & 17.87 & -- \\
\hline Intercept & 1 & -- & 8.33 \\
\hline A-Milk Fat & 1 & 13.37 & 0.261 \\
\hline B-Soya cake powder & 1 & 2.69 & -0.117 \\
\hline C-Sugar & 1 & 0.09 & -0.021 \\
\hline AB & 1 & 0.01 & 0.011 \\
\hline AC & 1 & 0.05 & 0.021 \\
\hline BC & 1 & 2.06 & 0.134 \\
\hline A^2 & 1 & 23.56 & -0.337 \\
\hline B^2 & 1 & 125.94 & -0.779 \\
\hline$C^{\wedge} 2$ & 5 & 9.12 & -0.21 \\
\hline Lack of Fit & & 1.59 & -- \\
\hline Std. Dev. & & 0.26 & -- \\
\hline Mean & & 7.43 & -- \\
\hline C.V. (\%) & & 3.55 & -- \\
\hline R-Squared & & 0.9415 & -- \\
\hline Adj R-Squared & & 0.8888 & -- \\
\hline Pred R-Squared & & 0.6951 & -- \\
\hline Adeq Precision & & 12.88 & -- \\
\hline PRESS & & 3.62 & -- \\
\hline Model & & Significant & -- \\
\hline
\end{tabular}

Table 3: Predicted score of the suggested formulation of soy fortified burfi by design Expert 8.0.3.1

\begin{tabular}{|l|c|c|c|c|c|}
\hline S. No. & Milk Fat (\%) & SCP (\%) & Sugar (\%) & Body \& Texture & Desirability \\
\hline 1 & 4.59 & 19.24 & 26.93 & 8.31 & 0.845 \\
\hline 2 & 4.59 & 19.77 & 27.01 & 8.3 & 0.832 \\
\hline 3 & 4.59 & 20.21 & 26.53 & 8.27 & 0.825 \\
\hline
\end{tabular}

Table 4: Constraints used for the formulation of soy fortified burfi by design Expert 8.0.3.1

\begin{tabular}{|l|l|c|c|c|c|c|}
\hline \multicolumn{1}{|c|}{ Name } & \multicolumn{1}{|c|}{ Goal } & $\begin{array}{c}\text { Lower } \\
\text { Limit }\end{array}$ & $\begin{array}{c}\text { Upper } \\
\text { Limit }\end{array}$ & $\begin{array}{c}\text { Lower } \\
\text { Weight }\end{array}$ & $\begin{array}{c}\text { Upper } \\
\text { Weight }\end{array}$ & Importance \\
\hline A-Milk Fat & is in range & 3 & 5 & 1 & 1 & 3 \\
\hline B-Soya Cake Powder & maximize & 10 & 30 & 1 & 1 & 4 \\
\hline C-Sugar & minimize & 25 & 35 & 1 & 1 & 3 \\
\hline Body \& Texture & maximize & 5.89 & 8.55 & 1 & 1 & 3 \\
\hline
\end{tabular}


a)

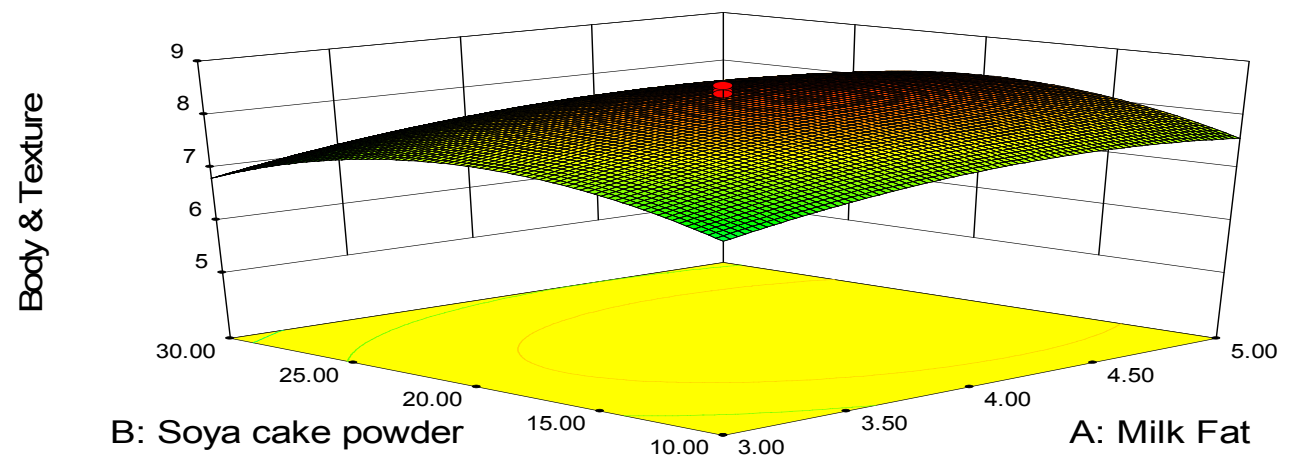

b)

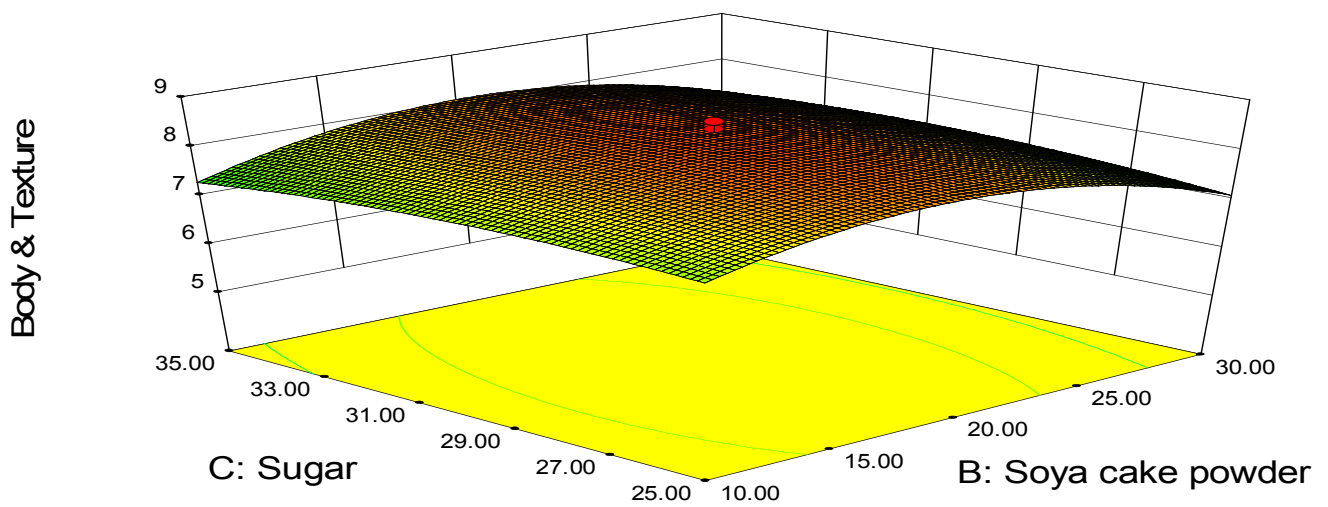

c)

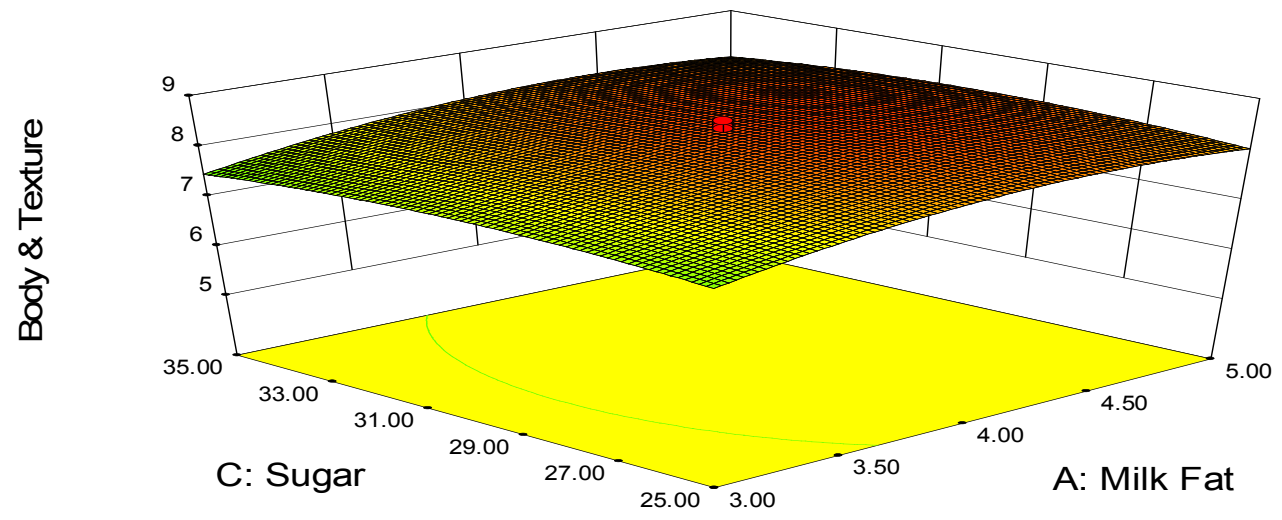

Fig.1: D plots representing the effect of milk fat, soy cake powder and sugar on body $\&$ texture of soy fortified burfi, (a) soy cake powder and milk fat, (b) soy cake powder and sugar, and (c) Sugar and milk fat. 

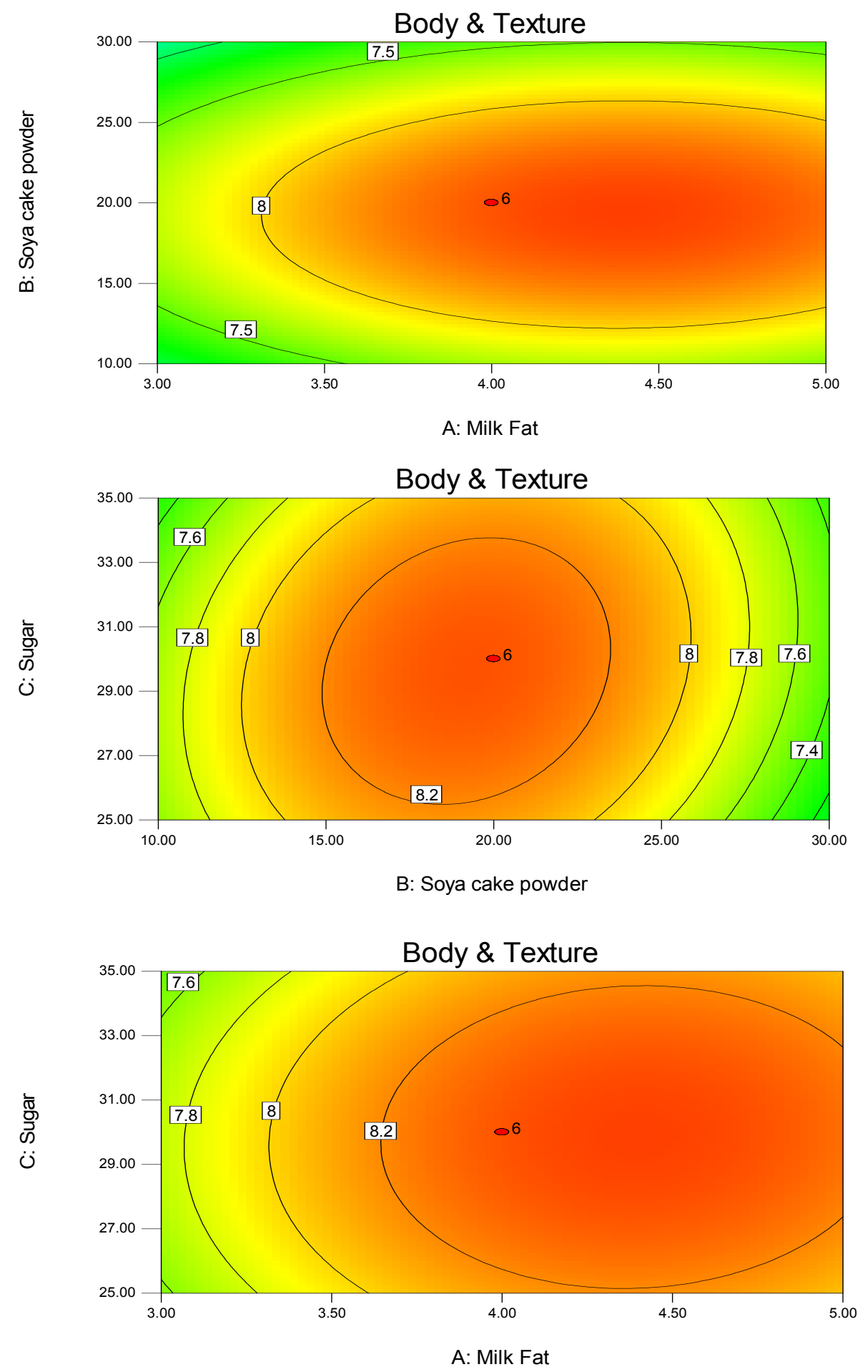

Fig. 2: Contour plot representing the effect of milk fat, soy cake powder and sugar on body \& texture of soy fortified burfi, (a) soy cake powder and milk fat, (b) soy cake powder and sugar, and (c) sugar and milk fat. 
a)

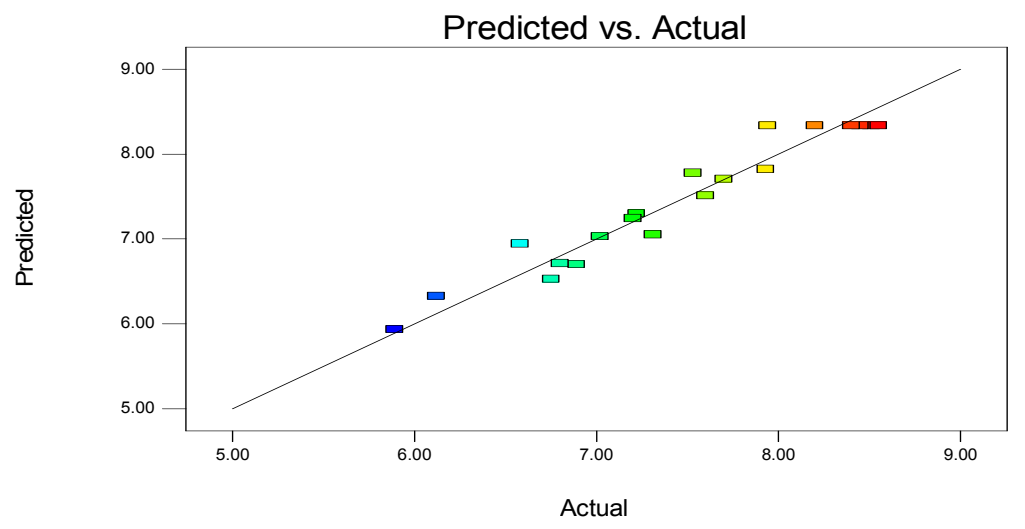

b)

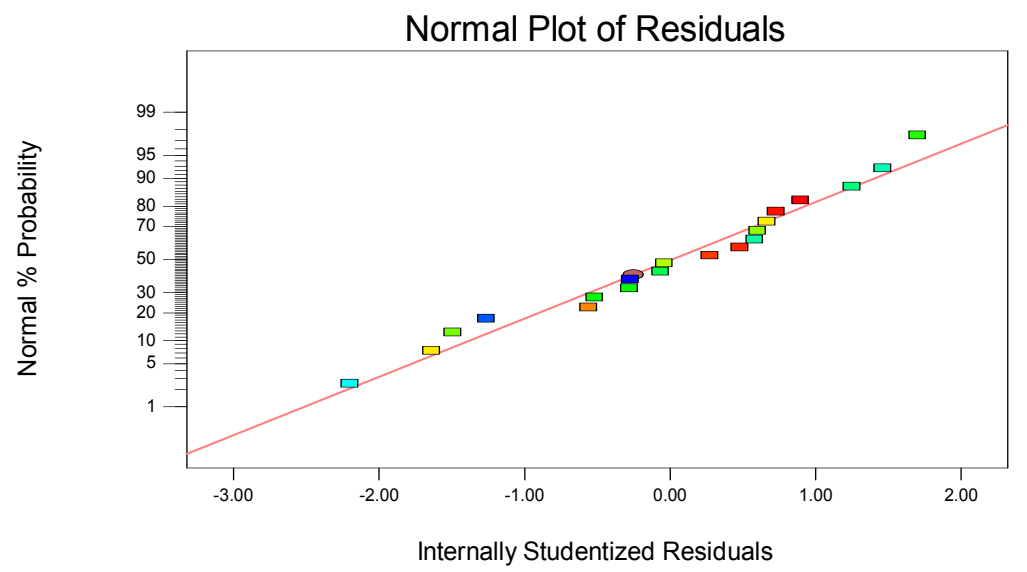

Fig. 3: (a) Actual versus predicted values and (b) normal probability plot for the body and texture of soy fortified burfi

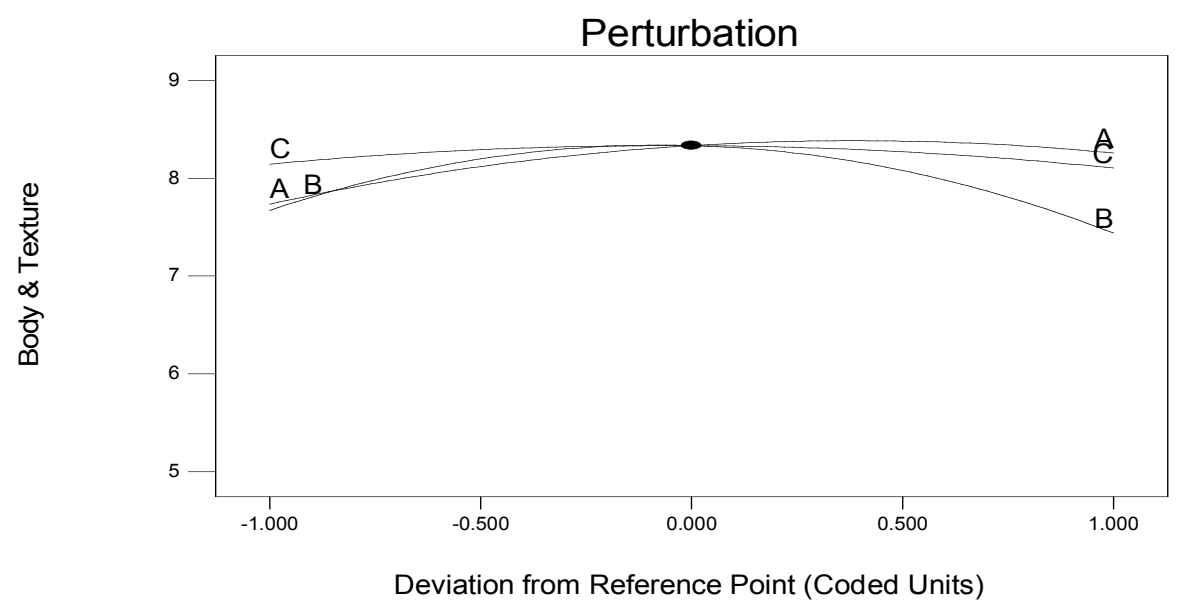

Fig. 4: Perturbation plots for the body and texture of soy fortified burfi 


\section{References}

1. Achi, O.K. (1999). Quality attributes of fermented yam flour supplemented with processed soy flour. Plant Foods for Human Nutrition, 54(2): 151158.

2. Addo, K., Bueton, D., Stuart, M.R., Bueton, H.R. and Hildebrand, D.F. (1993). Lipoxygenases known to improve quality of bread. Journal of Food Science, 58: 583-585.

3. Ahmad, A.L., Ismail, S. and Bhatia, S. (2005). Optimization of coagulationflocculation process for palm oil mill effluent using response surface methodology. Environmental Science and Technology, 39: 2828-2834.

4. Amerine, M.A., Pongborn, R.H. and Roescler, E.B. (1965). Principles of sensory evaluation of food. Academic Press, New York, pp. 338-339.

5. Anderson, J.W., Johnstone, B.M. and Cook-Newell, M.E. (1995). Meta-analysis of the effects of soy protein intake on serum lipids. The New England Journal of Medicine, 333: 276-282.

6. Anna, N.T., Plahar, W.A., Poll, L. and Jakob-Sen, M. (2005). Effect of soybean fortification on Ghanaian fermented maize dough aroma. International Journal of Food Science and Nutrition, 56(5): 315326.

7. Arora, S., Gawande, H., Sharma, V., Wadhwa, B.K., George, V., Sharma, G.S. and Singh, A.K. (2010). The development of burfi sweetened with aspartame. International Journal of Dairy Technology, 63: 127-135. DOI: 10.1111/j.1471-0307.2009.00555.x

8. Arora, S., Singh, V.P., Yarrakula, S., Gawande, H.N.K., Sharma, V., Wadhwa, S.K., Tomar, S.K. and Sharma, G.S. (2007). Textural and micro-structural properties of burfi made with various sweeteners, Journal of Texture Studies, 38: 684-697.

9. Chetana, R., Ravi, R. and Yella, R.S. (2010). Effect of processing variables on quality of milk burfi prepared with and without sugar. Journal Food Science Technology, 47(1): 114-118.
10. Dhingra, S. and Jood, S. (2002). Effect of supplementation of soy on physico chemical, sensory and nutritional characteristics of bread. Nutrition and health, 16: 313-39.

11. Gu, K. and Li, K.C. (2011). Preparation and evaluation of particleboard with a soy flour-polyethylenimine-maleic anhydride adhesive, Journal of the American Chemical Society. 88(5): 673-679.

12. Hardi, J., Slacanac, V. and Vlainic, M. (2001). Comparison of instrumental and sensory methods in fermented milk beverages texture quality analysis (Croatian). Mljekarsto, 51: 91-104.

13. Kadam, V.S., Kadam, R.M., Choudhari, D.M. and Pawar, B.K. (2010). Assessment of organoleptic characteristics and cost of Production of burfi prepared by using honey as natural sweetener. Journal of Dairying, Foods and Home Sciences, 29 (3/4):180-184.

14. Katara, R.V. and Bhargava, V.N. (1990). Yield and quality of Channa as influenced by addition of Soy milk, Asian journal of Dairy Research, 9: 189-199.

15. Khuri, K.H. and Cornell, J.A. (1987). Response surface designs and analysis, Marcell Decker, New York.

16. Kilara, A. (1998). Fats and fat substitutes. Indian Dairyman, 50: 7-15.

17. Lachance, P.A. (1994) .Human obesity. Food Technology, 48: 127-138.

18. Lin, Q., Chen, N., Bian, L. and Fan, M. (2012). Development and mechanism characterization of high performance soybased bio-adhesives. International Journal of Adhesion \& Adhesives, 34: 11-16.

19. Mason, R.L., Gunst, R.F. and Hess, J.L. (2003). Statistical Design and Analysis of Experiments, eighth applications to engineering and science, $2^{\text {nd }}$ ed., John Wiley, New York.

20. Masur, S.B., Tarachand, K.C. and Kulkarni, U. (2009). Comparative evaluation of full and defatted soy flour based bakery products. Karnataka Journal of Agricultural Sciences, 22(4): 937-938.

21. Mishra, P., Usha, M.S. and Singh, S. (1991) Soy-Wheat flour blends: Chemical rheological and baking characteristics. 
Journal of Food Science and Technology, 28(2): 89.

22. Montgomery, D.C. (1997). Design and Analysis of Experiments, 4th edition, John Wiley \& Sons, New York.

23. Sachdeva, S. and Rajhorhia, G.S. (1982). Technology and self-life of burfi. Indian Journal of Dairy Science, 35(4): 513-518.

24. Singh, A.K., Kadam, D.M., Saxena, M. and Singh, R.P. (2011). Effect of Soy Flour Supplementation on the Quality and Shelf Life of Gulabjamuns. International Journal of Food Science and Nutrition Engineering, 1(1): 11-17, DOI: 10.5923/j.food.20110101.04
25. Singh, J., Alam, T., Srivastava, P. and Yadav, R.K. (2010). Effect of blending soymilk with buffalo milk on the quality of paneer. Milchwissenschaft, 65(1): 6365.

26. Verma, T. (2014). Process optimisation of soy fortified burfi and its nutritional impact on rats. Ph.D. Thesis, A.H.D., I.(Ag).Sc, Banaras Hindu University, Varanasi, U.P., India.

27. Yanez, E., Ballester, D., Aguey and Way, H. (1982). Enrichment of bread with soybean flour, Archives catinoamenconus de Nutition, 30(2): 412. 